\title{
Potential of Jamu in Nanotechnology Perspective as an Alternative Treatment for Covid-19
}

\author{
Dhadhang Wahyu Kurniawan ${ }^{1 *}$, Azis Ikhsanudin ${ }^{2}$ \\ ${ }^{1}$ Department of Pharmacy, Faculty of Health Sciences, Universitas Jenderal Soedirman, Purwokerto, Indonesia \\ ${ }^{2}$ Universitas Ahmad Dahlan, Yogyakarta, Indonesia
}

\begin{abstract}
The world seems to be recovering at this time, especially because of the 2019 global coronavirus disease pandemic (COVID-19) caused by the Coronavirus 2 virus (SARS-CoV-2). This virus is similar to other $\beta$-coronaviruses through several steps to enter and bind angiotensin-converting enzyme 2 (ACE2) as the main receptor. This binding, particularly in the respiratory epithelium and alveoli of the lungs, affects harmony in human host cells. No specific vaccines and antivirals are available to date as drug investigations are still ongoing. However, many Indonesians consume herbal medicine, especially 'empon-empon' containing the Zingiberaceae family, to protect their health from COVID-19. So far, herbal medicine has shown good results to protect the Indonesian people in fighting SARS-CoV-2 empirically. In this review, we describe the characteristics of SARS-CoV-2, herbal ingredients that are active in fighting COVID-19, and applied nanotechnology challenges to COVID-19. Therefore, it is proposed to develop herbal medicine with a nanotechnology approach to increase the efficacy and potential of herbal medicine in fighting COVID-19. Moreover, the development of nanotechnology for Indonesian jamu will increase the value of Indonesian jamu and raise its reputation in the world.
\end{abstract}

Keywords: COVID-19; SARS-CoV-2; jamu, nanotechnology; 'empon-empon'

*corresponding author

Email: dhadhang.kurniawan@unsoed.ac.id

\section{INTRODUCTION}

The COVID-19 pandemic has become a world problem as a global pandemic, where this case was first discovered in Wuhan Province, China, in December 2019 (Khanna et al., 2020)(Munster et al., 2020). The new coronavirus is the sole agent causing a new infectious disease known as severe acute respiratory syndrome coronavirus2 (SAR-Cov2). Coronavirus-2 is the seventh strain of the Coronaviridae family (Fuzimoto \& Isidoro, 2020; Khanna et al., 2020). Coronavirus infections, including SARS-CoV2, can cause death due to pulmonary respiratory failure due to systemic cytokine storms (Liu \& Ying, 2020).

Secretion of several cytokines and mediators, such as interleukin (IL) -1 $\beta$, IL-6, IL-7, IL-8, IL-18, interferon (IFN) $-\gamma$, tumor necrosis factor (TNF) $-\alpha$, monocyte chemoattractant peptide (MCP) -1, and granulocytecolony stimulating factor (G-CSF) have been shown to increase in COVID-19 patients (Borish \& Steinke, 2003; Liu \& Ying, 2020). In addition, pro-inflammatory cytokines play an important role in the process of disease pathogenesis. Production of IL-1 $\beta$ occurs following viral attachment to a receptor such as a toll (TLR) and activation of the inflammasome. Elevated IL-6 levels are associated with the development of COVID-19, and monitoring of this cytokine may be a potential marker in the prognosis of high-risk patients. TNF- $\alpha$ also plays a stimulating role in the development of inflammation and increases in the blood and peripheral tissues of COVID-19 patients (Borish \& Steinke, 2003; Khanna et al., 2020). Studies on inflammatory diseases, such as Multiple sclerosis (MS), Inflammatory bowel disease (IBD), Rheumatoid arthritis (RA), and Ankylosing spondylitis (AS) have shown that increased production of IL-1 $\beta$, IL- 6 , IL-18, and TNF $-\alpha$ is directly related to disease activity. Therefore, it is speculated that the same applies to COVID-19, and the severity of the disease may be related to the production of inflammatory cytokines. The study was conducted to overcome this global pandemic to find drugs and antivirals (Liu \& Ying, 2020).

There is no specific antiviral recommended, there is no vaccine available, and there is no medication approved for the treatment of COVID-19 being today. At present, the treatment is focused on the symptomatic of the disease, and the patients who have a severe infection are treated by oxygen therapy. In respiratory failure cases, mechanical ventilation is needed, while hemodynamic support is crucial for septic shock management (Hamid et al., 2020). 
To treat COVID-19, the clinicians are using some of the drugs which potent to overcome this disease, not only the common antiviral such as remdesivir, favipiravir, and lopinavir-ritonavir that used against COVID-19 but also antimalarial such as chloroquine and hydroxychloroquine. As adjuvant therapies, dexamethasone and acetaminophen are using to fight SARS-CoV-2 as well. All of them are displaying acceptable outcomes; nevertheless, they still need more investigations to have the best treatment for COVID-19 (Pooladanda et al., 2020). So far, the main treatment for SARS-CoV-2 is using antivirals that prevent the virus from entering the cells and avoiding it from replication and the movement of infected cells to the others. Meanwhile, antibiotics have no contribution to defeating SARS-CoV-2 directly, but they could be helped if there is a secondary bacterial infection due to COVID-19 (Abd El-Aziz \& Stockand, 2020). All of the compounds that have a good potent for COVID-19 are being examined mainly regarding the efficacy and the safety to beat 2019-nCoV. One of the most promising compounds is remdesivir, an antiviral drug with an action mechanism via terminating the RNA transcription prematurely, then inhibits the viral replication result in disturbs the ability of the virus to reproduce themselves (Jean et al., 2020).

Another alternative that researchers have taken to address this case is to use convalescent plasma (CP) to treat COVID-19, the classic adaptive immunotherapy that has been used to prevent and treat many infectious diseases for more than one hundred years. This plasma treatment could be more effective for COVID-19 patients in the early stages before the virus can do more serious damage to the lungs. CP is a promising and safe, effective method for the treatment of recurring and recurring pathogens, especially in the absence of proven antiviral compounds or vaccines (Rojas et al., 2020). Concerning this approach, the FDA has permitted the use of blood plasma from patients who have recovered from COVID-19 with high titers of antibody immune response (Chen et al., 2020).

Researchers around the world are not only exploiting specific vaccines and antivirals chemically and biotechnology but also exploring natural products and/or herbal medicines to treat COVID-19 (Ang et al., 2020). The various viral infection steps and replication can be inhibited by natural products, although the mechanisms are not yet fully characterized. Natural products contribute to reducing morbidity and mortality due to $2019-\mathrm{nCoV}$ infection through their function as immunomodulators and suppressing the inflammatory process (McKee et al., 2020). Compounds that have the potential to inhibit coronavirus infection in humans include quercetin, myricetin, psoralidin, caffeic acid, tryptanthrin, lycorine, scutellarein, silvestrol, saikosaponin, isobavachalone, and griffithsin. If the therapeutic activity of lycorine as an antiviral is not more than the level of plasma toxic concentration, this compound could be a good choice against the coronavirus. However, small molecules identified as the most potent for coronavirus inhibitors are categorized as polyphenols, which consist of conjugated fusion rings (Mani et al., 2020).

Known as a country that has a large biodiversity, Indonesian researchers also hardly exploit natural products for the treatment of COVID-19. A typical Indonesian natural product called jamu which has been practiced for centuries to maintain health and treat diseases. During the pandemic, many people in Indonesia consumed herbal medicine as a weapon to combat SARS-CoV-2 and sofar, they have been healthy. However, the pharmacological activity associated with herbal medicine is quite abundant according to empirical data, so it is necessary to carry out further research to prove its efficacy scientifically and to ensure its safety (Elfahmi et al., 2014). To prevent cytokine storms, residents in several countries use herbs that have antiinflammatory activity, one of which is Indonesia.

People in Indonesia from generation to generation know and consume traditional medicine or better known as jamu. Jamu, which comes from the ancient Javanese word "jampi" (magic potion), is commonly consumed to relieve pain and inflammation or to treat chronic diseases, such as rheumatism and cancer. In Indonesia, hundreds of ethnic groups have developed their own traditional recipes, most of which are derived from medicinal plants. These plant-based medicines contain one ingredient or a mixture of several elements. Plants in the Zingiberaceae (ginger) family, including Curcuma, Kaempferia, Zingiber, Alpinia, Elattaria, and Costus, have become mainstay elements in herbal medicine, along with other vegetable ingredients. Consumption of herbal medicine during the Coronavirus Disease 2019 (COVID-19) pandemic increased sharply, resulting in an imbalance in supply with the demand for these ingredients. Jamu, which is a traditional Indonesian medicine that has been known from generation to generation, is thought to increase immunity, making it the most popular alternative treatment during this pandemic. Nanotechnology development to increase antiviral activity and many natural products have been developed in dealing with COVID -19. Nanotechnology development can be adapted to detect, treat, and prevent this disease (Chan, 2020). In addition, nanoparticles can enhance the therapeutic effect and minimize drug side effects. The properties of nanoparticles are significant in antiviral treatment where high drug concentrations are required and overcome their limitations, such as bioavailability (Milovanovic et al., 2017). 
Based on the description above, this review presents the results of nanotechnology modification to increase the efficacy of herbal medicine against SARS-CoV-2. Preparing jamu in nanotechnology will increase the value of the herbal medicine itself and provide a higher bioavailability as an alternative to fight COVID-19.

\section{METHODS}

This literature review was performed using the google search engine to find relevant references. The search terms encompass 'COVID-19', 'nanomedicine', 'herbal nanoformulations', 'herbal nanoparticles', 'jamu', 'natural products', 'herbal medicine', and 'herbal nanotechnology'. The period time for searching the references for this review is 11 May 2020 to 31 October 2020 .

\section{RESULTS AND DISCUSSION}

\section{The Characteristics of SARS-CoV-2}

The best way to treat COVID-19 is by knowing the characteristics of SARS-CoV-2 first, clearly. SARS$\mathrm{CoV}-2$ is the seventh coronavirus that is known to cause human disease. Coronavirus $(\mathrm{CoV})$ is a group of huge and enveloped viruses with positive-sense, singlestranded RNA genomes. $\mathrm{CoV}$ is a zoonotic pathogen that can infect humans via inter-species transmission. This virus could be divided into four types: alpha, beta, gamma, and delta coronavirus (Wang et al., 2020). Human coronavirus are dominatingly associate with upper respiratory tract illness with the range from mild to moderate condition include the common cold (Vellingiri et al., 2020). CoV represents a continuous pandemic threat; humans have experienced two CoV-related health security crises since 2002 (Chang et al., 2020), i.e. severe acute respiratory syndrome coronavirus (SARS-CoV) which appeared in China and the middle east respiratory syndrome coronavirus (MERS-CoV) which emerged in Saudi Arabia in 2012 (El Zowalaty \& Järhult, 2020).

Both SARS-CoV and SARS-CoV-2 are part of the $\beta$-genus of $\mathrm{CoV}$. An envelope-anchored spike protein mediates $\mathrm{CoV}$ and goes through into the host cells by binding to the host receptor firstly and after that merge the viral and the host membranes (Shereen et al., 2020). A fined receptor-binding domain (RBD) of SARS$\mathrm{CoV}$ spike particularly recognizes its host receptor angiotensin-converting enzyme 2 (ACE2) within the respiratory epithelium and alveoli of the lungs (Yan. et al., 2020). When compared with previously isolated SARS-CoV strains, 2019-nCoV tends to use the human ACE2 less efficiently than human SARS-CoV, which was found in 2002. But SARS-CoV-2 likely uses human ACE2 is more efficient than human SARS-CoV, which emerged in 2003. Since the ACE2-binding interaction has proven to be one of the foremost vital determinants of SARS-CoV infectivity, SARS-CoV-2 has developed the capacity to infect humans and several capabilities to transmit among humans (Wan et al., 2020).

\section{Processing of Transmission of SARS COV-2 to Host Cells}

The process of SARS-CoV2 infection in host cells requires a special receptor, the ACE2 receptor. The interaction process between viral proteins and host cell ACE2 receptors is the first step in infection. Henceforth, the virus will have access to the host cytosol by carrying out proteolytic cleavage, where this process is influenced by the amount of acid from the spike protein by cathepsin or other proteases (Nugraha et al., 2020). The spike protein cleavage process occurs at two sites in the S2 portion. The first cleavage has a function of separating the RBD domains with $\mathrm{S}$ protein fusion, and the second cleavage serves to expose the fusion or splitting peptides in $\mathrm{S} 2$. The fusion between the virus and the host cell usually occurs within the endosome, which is acidified. This process is followed by the joining of two heptad replicates in S2 to form a six-helix antiparallel bundle. Overall, the occurrence of new S1 and S2 insertions is likely to influence the increase in spike protein cleavage by some proteases beyond that for other SARS-like viruses. The formation of the bundle leads to the mixing of the viral cell membrane and the host cell and results in the fusion and release of the viral genome into the cytoplasm (Huang et al., 2020; Jaimes et al., 2020).

\section{Jamu for COVID-19}

Naturally, there are hundreds of herbs that have been known to possess a significant amount of antiviral activity when used. They may be readily available in the garden or in the local market, and the others may prove quite hard to find. Olive leaf, balm from lemon leaf, ginger, chlorella, chamomiles, cayenne pepper, bilberry, black cohosh, chili, garlic, astragalus, licorice root, etc. are known used as antiviral, traditionally (James, 2015).

More advances, Traditional Chinese Medicine (TCM) was used to prevent and treat SARS in 2003 and also for the treatment of H1N1 infection in 2009. According to these experiences, TCM has been widely used in Chinese hospitals now to treat COVID-19. So far, the intervention of TCM can reduce the severe symptoms of patients $(\mathrm{Xu}$ \& Zhang, 2020). However, the observation on SARS patients with emerging COVID-19 treated by TCM excluded the safety aspect. Considering the information that several herbs used in the TCM contain nephrotoxins and mutagens; meanwhile, the toxicological properties of most Chinese herbal medicines must still be fully understood (Yang et al., 2020). 
Many natural products have good efficacy against viral infection as they can influence the role of viral proteins associated with virulence. Most of them have a common mechanism as an antiviral agent by inhibiting the viral replications. Chemical compounds from natural products such as lycorine, homoharringtonine, silvestrol, ouabain, tylophorine, and 7-methoxycrptopleurine have antiviral activity in the nanomolar concentration and could be lead for further drug development (Islam et al., 2020).

During the pandemic, many people in Indonesia consumed 'empon-empon' as an alternative to protect themselves and to defeat COVID-19. 'Empon-empon' has a closed connection to jamu and more specific, 'empon-empon' is a part of jamu. 'Empon-empon' has two meanings (Riswan \& Sangat-Remantyo, 2002), those are:

- Empon-empon is yard medicinal plants. Almost every family in the village in Java island has its own yard to cultivate medicinal plants. Hence, they can reach 'empon-empon' easily and use it to protect their health and curing their illness at any time.

- Empon-empon is also a group of medicinal plants belonging to the ginger family (Zingiberaceae) such as ginger (Zingiber officinale Roscoe), turmeric (Curcuma longa L.), Javanese turmeric (Curcuma xanthorriza), greater galingale (Kaempferia galanga L.), and galingale (Alpinia galanga (L.). Some of them are used for flavors, dyes, spices, and ornamental plants.

Empon-empon containing bioactive curcumin, which has known for its therapeutic potential as an antibacterial, antifungal, and antiviral (Moghadamtousi et al., 2014). Curcumin is a complex molecule with numerous biological targets and diverse cellular effects, such as anti-inflammation, antioxidant, and anti-cancer. Furthermore, curcumin is non-toxic for humans at high doses (Epstein et al., 2010). Conforming to these investigations, 'empon-empon' has a good promising as a therapeutic agent for the treatment of COVID-19. Herbal medicine consists of several herbal mixtures, which are formulated with certain comparisons based on hereditary experiences. Herbal plants, as raw materials for herbal medicine, have been proven to have antiviral, anti-inflammatory, antibacterial activity, and so on. Several studies were conducted to prove that herbal plants, especially herbs, can be used as an alternative to the prevention and antiviral treatment of SAR CoV-2, either through pre-clinical or clinical approaches. Some herbal raw material plants as candidates for SAR CoV-2 antiviral can be seen in Table 1 .

\section{Nanotechnology for COVID-19}

Nanotechnology approaches have been explored as a therapeutic agent against coronavirus, include nanomaterial, nanoparticles, nanocomposites, etc. The development of $\mathrm{Ag}$ nanomaterials is a novel therapeutic approach to fight the alpha-CoV porcine epidemic diarrhea virus (PEDV) was first introduced in 2018. This study illustrated that $\mathrm{Ag}_{2} \mathrm{~S}$ nanoclusters (NCs) might control the proliferation of PEDV in treated Vero cells. The result showed that prevention of the viral growth and inhibition of synthesis of viral negative-strand RNA is associated with the treatment with $\mathrm{Ag}_{2} \mathrm{~S}$ NCs. The $\mathrm{Ag}_{2} \mathrm{~S}$ NCs also demonstrated definitely govern interferon (IFN)-stimulating gene proliferation and clearly regulate the expression of pro-inflammatory cytokines. These processes provoked the protection of the cells from PEDV infection and proposed that $\mathrm{Ag}_{2} \mathrm{~S}$ NCs could be a great choice as a therapy tool for the next investigation (Du et al., 2018).

Nanoformulation has been deployed for diphyllin as a therapeutic agent to cure feline infectious peritonitis (FIP), disease because of feline coronavirus. By inhibiting the acidification of endosomal in fcwf-4cells, diphyllin is a vacuolar ATPase that could halt the uncoating of the virus and break the cellular virus entry. Diphyllin formulated with poly(ethylene glycol)-blockpoly(lactide-coglycolide) as a nanocarrier improved the diphyllin inhibitory activity against FIP and increased the safety profile. This study displayed that nanoformulation of diphyllin was successful in defeating coronavirus and the results suggested that the approach could be a promising treatment to overcome $\mathrm{CoV}$ infection $(\mathrm{Hu}$ et al., 2017). Furthermore, a nanospheres/microspheres (NS/MS) using a device from biopolymeric material having a great promising to beat coronavirus was developed to tackle human coronavirus NL63 (Chen et al., 2016).

Thereby, it can be concluded that nanotechnology could improve antiviral applications against vary of coronavirus. Nonetheless, it is needed more studies about the treatment for COVID-19 using nanomedicines, deeply, and comprehensively (Nikaeen et al., 2020).

\section{Nanotechnology in Jamu}

Nanotechnology is identic to nanoparticles; in the nano size, particles have different properties as compared to the macro size. The role of nanoparticles is applied to all of the matter, include natural products. The effectiveness of natural products in the prevention and treatment of diseases could be improved by making them into 
Table 1. Herbal raw material plants as candidates for $\mathrm{SAR} \mathrm{CoV}-2$ antiviral

\begin{tabular}{|c|c|c|c|}
\hline Material & Active compound & $\begin{array}{l}\text { Prediction interaction of active compounds } \\
\text { with SAR-Cov-2 }\end{array}$ & References \\
\hline Zingiber officinale & 6 - Gingerol & $\begin{array}{l}\text { Gingerol exhibits binding affinity of }-11.4082 \\
\text { KJ/mol, -12.9523 KJ/mol and }-12.8835 \mathrm{KJ} / \\
\text { mol with COVID-19 viral RNA binding } \\
\text { protein (6W4B), N Terminal RNA Binding } \\
\text { Protein (6VSB), Spike glycoprotein (6M3M) } \\
\text { respectively. Molecular interaction between } \\
\text { COVID-19 viral spike glycoprotein with } \\
\text { Gingerol forms hydrogen-bonded interaction } \\
\text { with Glu63, Arg89, Thr92, Asp129 residues } \\
\text { and form non bonded interaction with Glu63, } \\
\text { Lys66, Arg89, Thr92, Leu168, Pro169 residues } \\
\text { of COVID-19 spike glycol protein. } \\
\text { Molecular interaction between COVID-19 viral } \\
\text { RNA binding protein with Gingerol makes } \\
\text { hydrogen bonded interaction with Val42, } \\
\text { Pro58, Ser60, Thr68 residues and form non } \\
\text { bonded interaction with Arg40, Phe41, Val42, } \\
\text { Phe57, Pro58, Lys59, Ser60, Ile66, Thr68, Ile92 } \\
\text { residues of COVID-19 spike glycol protein. }\end{array}$ & $\begin{array}{l}\text { (Nugraha et al., 2020; } \\
\text { Rathinavel et al., 2020) }\end{array}$ \\
\hline Black pepper & Piperdardiine & $\begin{array}{l}\text { Piperdardiine exhibited interactions with } \\
\text { COVID19 and the residues SER46, MET49, } \\
\text { HIE41, GLN189, ARG189, ASP187, MET165, } \\
\text { HIE164, THR24, THR25, LEU27, ASN142, } \\
\text { and GLY143 play a crucial role in binding with } \\
\text { ligands. }\end{array}$ & $\begin{array}{l}\text { (Nandi \& Mitra, 2020; } \\
\text { Rajagopal et al., n.d.) }\end{array}$ \\
\hline Curcuma longa & Curcumin & $\begin{array}{l}\text { The anti-inflammatory mechanism of curcumin } \\
\text { is to inhibit the production and release of pro- } \\
\text { inflammatory cytokines, such as IL-1, IL-6, } \\
\text { IL-8, TNF-a. Meanwhile, dissolved curcumin } \\
\text { directly into the lungs dramatically reduced } \\
\text { the pro-inflammatory cytokines IL-1b, IL-6, } \\
\text { TNF-a in LAB cells, lungs and serum of mice } \\
\text { with severe pneumonia caused by Klebsiella. } \\
\text { In addition, curcumin also decreases the } \\
\text { expression of many other inflammatory } \\
\text { mediators, including MCP1 (CCL2), MIPI1 } \\
\text { (CCL3), GROa (CXCL1), GROb (CXCL2), } \\
\text { IP10 (CXCL10), SDF1 (CXCL12), MMP-2, } \\
\text { IFN-g., and MMP-9, which regulates immune } \\
\text { cell activity and inflammatory response and } \\
\text { increases fibrosis in the lungs after infection. }\end{array}$ & $\begin{array}{l}\text { (Liu \& Ying, 2020; } \\
\text { Nugraha et al., 2020) }\end{array}$ \\
\hline Curcuma longa & Xanthorrhizol & $\begin{array}{l}\text { Xanthorrhizol has anti-inflammatory activity by } \\
\text { inhibiting inflammatory cytokines in adipose } \\
\text { tissue and expression of tumor necrosis factor } \\
(\text { TNF- } \alpha \text { ). Research has shown that xanthorrhizol } \\
\text { prevents recruitment of immune cells into } \\
\text { adipose tissue to downregulate inflammatory } \\
\text { cytokine genes. Xanthorrhizol also has the } \\
\text { activity of reducing interleukin (IL-1 } \beta \text { ) gene } \\
\text { expression in muscle. Other studies have shown } \\
\text { that xanthorrhizol can reduce serum IL-6 levels } \\
\text { and increase serum transformation growth factor } \\
\text { (TGF- } \beta \text { ) in patients with SLE with hypovitamin } \\
\text { D. }\end{array}$ & $\begin{array}{l}\text { (Kim et al., 2014; } \\
\text { Nugraha et al., 2020) }\end{array}$ \\
\hline
\end{tabular}


Table 1. (continued)

\begin{tabular}{|c|c|c|c|}
\hline Material & Active compound & $\begin{array}{l}\text { Prediction interaction of active compounds } \\
\text { with SAR-Cov-2 }\end{array}$ & References \\
\hline Citrus fruit & Naringin & $\begin{array}{l}\text { Naringin pretreatment significantly inhibited } \\
\text { LPS-induced expression of HMGB1 protein } \\
\text { and proinflammatory cytokines (COX-2, iNOS, } \\
\text { IL-1 } \beta \text { and IL-6) expression in vitro. HMGB1 } \\
\text { is a ubiquitous DNA-binding core protein and } \\
\text { can be actively released by immune cells, such } \\
\text { as macrophages and monocytes, following } \\
\text { inflammatory stimuli. HMGB1 also acts as a } \\
\text { pro-inflammatory cytokine and regulates the } \\
\text { storm of cytokines, up-regulating cytokines } \\
\text { such as TNF- } \alpha \text {, IL- } 6 \text {, IL-1 } \beta \text {, and IL-8. }\end{array}$ & (Cheng et al., 2020) \\
\hline
\end{tabular}

nanoparticles. One of the main reasons regarding the effectiveness of nanoparticles is the improvement of bioavailability. Having a good bioavailability will improve the pharmacokinetic profile that results in better therapeutic effects (Zhang et al., 2015).

Sulistyo and colleagues (2017) observed that green tea nanoparticles have better effects in ironized mouse model thalassemia as compared to the green tea as a free compound. The green tea extract prepared into nanoparticles using chitosan as a carrier crosslinked with sodium tripolyphosphate (Sulistyo et al., 2017).

Another benefit of the application of nanoparticles in the delivery of natural compounds is the system can reach the specific target sites such as certain tissues, organs, and cells. Delivery of natural products with nanoparticles device gives critical impacts, especially minimizing the adverse effects of the active substances. Using a self-nano emulsifying drug delivery system (SNEDDS), quercetin demonstrated a protective effect against liver damage. The histopathological observation displayed that the inflammatory infiltrations induced by paracetamol significantly ameliorated (Ahmed et al., 2014).

Nanoparticles can also deliver the natural products with controlled release, mainly by formulating the herbal with a polymer as a carrier. Formulation of acerola, guava, and passion fruits by-products inside PLGA (poly(DLlactide-co-glycolide) matrix demonstrated an initial burst then gradually followed by a slower rate. The release of the drug from the nanoparticles at a controlled rate is a crucial key since the drug release kinetics determine the concentration of the drug in the target site (Silva et al., 2014).

All of the natural products in Indonesia which have therapeutic effects as a medicine empirically are categorized as jamu. Accordingly, the efficacy and the value of jamu should be improved using nanotechnology approaches. Various methods of preparation of nanotechnology approaches could be applied in jamu i.e., nanosuspension, nanopolymerization, oil, solvent, and surfactant-co-surfactant mixture, self-nanoemulsion, nanoprecipitation, ultrasonication, solvent emulsion and evaporation, hot homogenization, nanoencapsulation, nanofiber fabrication, electrospinning, and spray drying (Gopi \& Amalraj, 2016).

\section{CONCLUSION}

Jamu is a traditional Indonesian medicine made from a mixture of several plants such as 'empon-empon', which has been used for generations in Indonesia as a supplement or medicine to increase endurance and cure diseases. During the pandemic, many people in Indonesia consumed 'empon-empon' to protect themselves from SARS-CoV-2. Further evidence-based research in Jamu is needed to conform its efficacy. Through a nanotechnology approach, the value and potential of Jamu can be increased and become a promising therapeutic option for the treatment of COVID-19. Moreover, the development of nanotechnology for Indonesian jamu will increase the value of Indonesian jamu and raise its reputation in the world.

\section{REFERENCES}

Abd El-Aziz, T. M., \& Stockand, J. D. (2020). Recent progress and challenges in drug development against COVID-19 coronavirus (SARS-CoV-2) - an update on the status. Infection, Genetics and Evolution: Journal of Molecular Epidemiology and Evolutionary Genetics in Infectious Diseases, 83, 104327. https://doi. org/10.1016/j.meegid.2020.104327

Ahmed, O. A. A., Badr-Eldin, S. M., Tawfik, M. K., Ahmed, T. A., El-Say, K. M., \& Badr, J. M. (2014). Design and optimization of self-nanoemulsifying 
delivery system to enhance quercetin hepatoprotective activity in paracetamol-induced hepatotoxicity. Journal of Pharmaceutical Sciences, 103(2), 602-612. https:// doi.org/10.1002/jps.23834

Borish, L. C., \& Steinke, J. W. (2003). 2. Cytokines and chemokines. The Journal of Allergy and Clinical Immunology, 111(2 Suppl), S460-S475. https://doi. org/10.1067/mai.2003.108

Chang, D., Lin, M., Wei, L., Xie, L., Zhu, G., Dela Cruz, C. S., \& Sharma, L. (2020). Epidemiologic and clinical characteristics of novel coronavirus infections involving 13 patients outside Wuhan, China. JAMA - Journal of the American Medical Association, 323(11), 1092-1093. https://doi.org/10.1001/jama.2020.1623

Chen, Y. N., Hsueh, Y. H., Hsieh, C. Te, Tzou, D. Y., \& Chang, P. L. (2016). Antiviral activity of graphene-silver nanocomposites against non-enveloped and enveloped viruses. International Journal of Environmental Research and Public Health, 13(4), 430. https://doi. org/10.3390/ijerph13040430

Cheng, L., Zheng, W., Li, M., Huang, J., Bao, S, Xu, Q., \& Ma, Z. (2020). Citrus fruits are rich in flavonoids for immunoregulation and potential targeting ACE2. Preprints 2020, 2020020313

Du, T., Liang, J., Dong, N., Lu, J., Fu, Y., Fang, L., Xiao, S., \& Han, H. (2018). Glutathione-Capped Ag2S nanoclusters inhibit coronavirus proliferation through blockage of viral RNA synthesis and budding. ACS Applied Materials \& Interfaces, 10(5), 4369-4378. https://doi.org/10.1021/acsami.7b13811

El Zowalaty, M. E., \& Järhult, J. D. (2020). From SARS to COVID-19: A previously unknown SARS- related coronavirus (SARS-CoV-2) of pandemic potential infecting humans - Call for a One Health approach. One Health, 9(February), 100124. https://doi.org/10.1016/j. onehlt.2020.100124

Epstein, J., Sanderson, I. R., \& MacDonald, T. T. (2010). Curcumin as a therapeutic agent: The evidence from in vitro, animal and human studies. British Journal of Nutrition, 103(11), 1545-1557. https://doi.org/10.1017/ S0007114509993667

Fuzimoto, A. D., \& Isidoro, C. (2020). The antiviral and coronavirus-host protein pathways inhibiting properties of herbs and natural compounds - Additional weapons in the fight against the COVID-19 pandemic? Journal of Traditional and Complementary Medicine, 10(4), 405419. https://doi.org/10.1016/j.jtcme.2020.05.003
Gopi, S., Amalraj, A, Haponluk, J.T., \& Thomas, S. (2016). Introduction of nanotechnology in herbal drugs and nutraceutical: A Review. Journal of Nanomedicine \& Biotherapeutic Discovery, 6(2), 1-8. https://doi. org/10.4172/2155-983x.1000143

Hu, C. M. J., Chang, W. S., Fang, Z. S., Chen, Y. T., Wang, W. L., Tsai, H. H., Chueh, L. L., Takano, T., Hohdatsu, T., \& Chen, H. W. (2017). Nanoparticulate vacuolar ATPase blocker exhibits potent host-targeted antiviral activity against feline coronavirus. Scientific Reports, 7(1), 1-11. https://doi.org/10.1038/s41598017-13316-0

Huang, Y., Yang, C., Xu, X. feng, Xu, W., \& Liu, S. wen. (2020). Structural and functional properties of SARS-CoV-2 spike protein: potential antivirus drug development for COVID-19. Acta Pharmacologica Sinica, 41(9), 1141-1149. https://doi.org/10.1038/ s41401-020-0485-4

Islam, M. T., Sarkar, C., El-Kersh, D. M., Jamaddar, S., Uddin, S. J., Shilpi, J. A., \& Mubarak, M. S. (2020). Natural products and their derivatives against coronavirus: A review of the non-clinical and pre-clinical data. Phytotherapy Research : PTR, 34(10), 2471-2492. https://doi.org/10.1002/ptr.6700

Jaimes, J. A., Millet, J. K., \& Whittaker, G. R. (2020). Proteolytic cleavage of the SARS-CoV-2 spike protein and the role of the novel S1/S2 site. IScience, 23(6), 101212. https://doi.org/10.1016/j.isci.2020.101212

James, M. (2015). Natural antibiotics and antivirals: the ultimate guide to natural antibiotics - Homemade herbal remedies that kill pathogens and cure bacterial infections and allergies. Prevent Illness, Cold and Flu. CreateSpace Independent Publishing Platform.

Khanna, K., Kohli, S. K., Kaur, R., Bhardwaj, A., Bhardwaj, V., Ohri, P., Sharma, A., Ahmad, A., Bhardwaj, R., \& Ahmad, P. (2020). Herbal immune-boosters: Substantial warriors of pandemic Covid-19 battle. Phytomedicine, 153361. Advance online publication. https://doi.org/10.1016/j.phymed.2020.153361

Kim, M. B., Kim, C., Song, Y., \& Hwang, J. K. (2014). Antihyperglycemic and anti-inflammatory effects of standardized Curcuma xanthorrhiza Roxb. Extract and its active compound xanthorrhizol in high-fat dietinduced obese mice. Evidence-Based Complementary and Alternative Medicine, 2014, 205915. https://doi. org/10.1155/2014/205915 
Liu, Z., \& Ying, Y. (2020). The inhibitory effect of curcumin on virus-induced cytokine storm and its potential use in the associated severe pneumonia. Frontiers in Cell and Developmental Biology, 8, 479. https://doi.org/10.3389/fcell.2020.00479

Moghadamtousi, S. Z., Kadir, H. A., Hassandarvish, P., Tajik, H., Abubakar, S., \& Zandi, K. (2014). A review on antibacterial, antiviral, and antifungal activity of curcumin. Biomed Research International, 2014, 186864. https://doi.org/10.1155/2014/186864

Morawska, L., \& Cao, J. (2020). Airborne transmission of SARS-CoV-2: The world should face the reality. Environment International, 139(April), 105730. https:// doi.org/10.1016/j.envint.2020.105730

Munster, V. J., Koopmans, M., van Doremalen, N., van Riel, D., \& de Wit, E. (2020). A novel coronavirus emerging in China - Key questions for impact assessment. New England Journal of Medicine, 382(8), 692-694. https://doi.org/10.1056/NEJMp2000929

Nandi, D.K., \& Mitra, M. (2020). Herbal gold nanoparticles for attenuating pandemic infection of COVID-19 virus. Journal of Nanomedicine \& Nanotechnology, 11:547, 9-10. https://doi. org/10.35248/2157-7439.20.11.547

Nikaeen, G., Abbaszadeh, S., \& Yousefinejad, S. (2020). Application of nanomaterials in treatment, anti-infection and detection of coronaviruses. Nanomedicine (London, England), 15(15), 1501-1512. https://doi.org/10.2217/ nnm-2020-0117

Nugraha, R. V., Ridwansyah, H., Ghozali, M., Khairani, A. F., \& Atik, N. (2020). Traditional herbal medicine candidates as complementary treatments for COVID-19: A Review of Their Mechanisms, Pros and Cons. Evidence-Based Complementary and Alternative Medicine, 2020. https://doi.org/10.1155/2020/2560645

Parry, J. (2020). China coronavirus: cases surge as official admits human to human transmission. BMJ (Clinical Research Ed.), 368(January), m236. https:// doi.org/10.1136/bmj.m236

Rajagopal, K., Byran, G., Jupudi, S., \& Vadivelan, R. (2020). Activity of phytochemical constituents of black pepper, ginger, and garlic against coronavirus (COVID-19): An in silico approach. International Journal of Health \& Allied Sciences, 9(5), 43-50

Rathinavel, T., Palanisamy, M., Palanisamy, S., Subramanian, A., \& Thangaswamy, S. (2020). Phytochemical 6-Gingerol - A promising Drug of choice for COVID-19. International Journal of Advanced Science and Engineering, 06(04), 1482-1489. https:// doi.org/10.29294/ijase.6.4.2020.1482-1489

Riou, J., \& Althaus, C. L. (2020). Pattern of early human-to-human transmission of Wuhan 2019 novel coronavirus (2019-nCoV), December 2019 to January 2020. Eurosurveillance, 25(4), 1-5. https://doi. org/10.2807/1560-7917.ES.2020.25.4.2000058

Riswan, S., \& Sangat-Remantyo, H. (2002). Jamu as traditional medicine in Java, Indonesia. In South Paciflc Study, 123 (1), 1-10

Shereen, M. A., Khan, S., Kazmi, A., Bashir, N., \& Siddique, R. (2020). COVID-19 infection: Origin, transmission, and characteristics of human coronaviruses. Journal of Advanced Research, 24, 91-98. https://doi. org/10.1016/j.jare.2020.03.005

Silva, L. M., Hill, L. E., Figueiredo, E., \& Gomes, C. L. (2014). Delivery of phytochemicals of tropical fruit by-products using poly (dl-lactide-co-glycolide) (PLGA) nanoparticles: Synthesis, characterization, and antimicrobial activity. Food Chemistry, 165, 362-370. https://doi.org/10.1016/j.foodchem.2014.05.118

Sulistyo, H., Kurniawan, D. W., \& Rujito, L. (2017). Biochemical and histopathological effects of green tea nanoparticles in ironized mouse model. Research in Pharmaceutical Sciences, 12(2), 99-106. https://doi. org/10.4103/1735-5362.202448

Vellingiri, B., Jayaramayya, K., Iyer, M., Narayanasamy, A., Govindasamy, V., Giridharan, B., Ganesan, S., Venugopal, A., Venkatesan, D., Ganesan, H., Rajagopalan, K., Rahman, P. K. S. M., Cho, S. G., Kumar, N. S., \& Subramaniam, M. D. (2020). COVID-19: A promising cure for the global panic. Science of the Total Environment, 725, 138277. https://doi.org/10.1016/j. scitotenv.2020.138277

Wan, Y., Shang, J., Graham, R., Baric, R. S., \& Li, F. (2020). Receptor Recognition by the Novel Coronavirus from Wuhan: an Analysis Based on Decade-Long Structural Studies of SARS Coronavirus. Journal of Virology, 94(7), 1-9. https://doi.org/10.1128/jvi.0012720

Wang, Q., Zhang, Y., Wu, L., Niu, S., Song, C., Zhang, Z., Lu, G., Qiao, C., Hu, Y., Yuen, K. Y., Wang, Q., Zhou, H., Yan, J., \& Qi, J. (2020). Structural and Functional Basis of SARS-CoV-2 Entry by Using Human ACE2. Cell, 181(4), 894-904.e9. https://doi.org/10.1016/j. cell.2020.03.045 
Watkins, R., Wu, L., Zhang, C., Davis, R., Xu, B. (2015). Natural product-based nanomedicine: recent advances and issues. International Journal of Nanomedicine. 10(1), 6055-6074. https://doi.org/10.2147/IJN.S92162

Xu, J., \& Zhang, Y. (2020). Traditional chinese medicine treatment of COVID-19. Complementary Therapies in Clinical Practice, 39, 101165. https://doi.org/10.1016/j. ctcp. 2020.101165

Yang, Y., Islam, M. S., Wang, J., Li, Y., \& Chen, X. (2020). Traditional chinese medicine in the treatment of patients infected with 2019-new coronavirus (SARS-
CoV-2): A Review and Perspective. International Journal of Biological Sciences, 16(10), 1708-1717. https://doi.org/10.7150/ijbs.45538

Yan, R., Zhang, Y., Li, Y., Xia, L., Guo, Y., \& Zhou, Q. (2020). Structural basis for the recognition of SARSCoV-2 by full-length human ACE2. Science (New York, N.Y.), 367(6485), 1444-1448. https://doi.org/10.1126/ science.abb2762 